Proc. Estonian Acad. Sci. Eng., 2006, 12, 2, 134-146

\title{
Rotational viscometry for the study of urea-formaldehyde resins
}

\begin{abstract}
Aime Suurpere, Peep Christjanson and Kadri Siimer
Department of Polymer Materials, Tallinn University of Technology, Ehitajate tee 5, 19086 Tallinn, Estonia; suurpere@staff.ttu.ee

Received 30 November 2005

Abstract. Rotational viscometry as a generally recognized method for rheological measurements of non-Newtonian liquids was used for the study of commercial urea-formaldehyde resins. The measurement results were analysed using the power law function with evaluation of the consistency and flow indices. The resins were observed during their storage until alkali-promoted polycondensation led to gelation. It is suitable to differentiate two periods in the course of the polycondensation process - the initial period of slow viscosity growth and the following period of fast structuration. Regularity in the change of values of the flow index, calculated from data obtained with two rotational viscometer models, permits to characterize the flow behaviour of ureaformaldehyde resins in the initial period of polycondensation. The results of the rheokinetic study were compared with the data obtained with standard methods. In the relationships trends were found, which are consistent with conceptions about the formation of the resin structure and processes, occurring during the initial period of polycondensation.
\end{abstract}

Key words: rotational viscometry, rheokinetics, urea-formaldehyde resins, polycondensation.

\section{INTRODUCTION}

In all technological processes, in which liquid materials participate, an important characteristic is flowability. For viscosity measurements, many methods and different devices have been used for a long time $\left[{ }^{1,2}\right]$. Both producers and researchers agree that viscosity as a characteristic of fluids is closely associated with the structure of the substance. Nevertheless, flow behaviour is an indirect measure of product consistency and quality. Single-point measurements, which are mostly used for quality control, cannot adequately characterize behaviour and structure-property relationships of non-Newtonian liquids. Therefore the use of multipoint techniques is strongly recommended in studies of materials with 
complicated structure such as adhesive resins, etc. Mathematical relationships between the viscosity parameters, chemical and physical structure and technological properties of liquid resins are the problems still worth to study.

Urea-formaldehyde (UF) plastics are known since 1915 (in production since 1928) and are till now widely used as adhesive resins in industry. A great progress has been made in the field of study of UF resins thanks to the application of the ${ }^{13} \mathrm{C}$ NMR spectroscopy $\left[{ }^{3-5}\right]$. However, there have been relatively few studies on the rheological behaviour of UF resins and much remains unclear in that field $\left[{ }^{6,7}\right]$. In earlier studies on rheological behaviour of UF resins, made in our laboratory, the industrial resins with a low F/U ratio (1.03-1.08) and laboratory resins with similar standard characteristics were investigated. Rotational viscometry as a generally recognized method for rheological measurements of non-Newtonian liquids was used in these studies. The measurement results were analysed according to the power law relationship between the shear stress $\tau$ and the shear deformation rate $\dot{\gamma}$

$$
\tau=K \dot{\gamma}^{n},
$$

where $K$ is the consistency index and $n$ is the flow index.

The resins were observed during their storage until alkali-promoted polycondensation led to gelation $\left[{ }^{8,9}\right]$.

The purpose of the present study was to examine the possibilities of rotational viscometry to characterize properties of UF resins from the standpoint of structure, molar mass and molar mass distribution. The latter is essential to know, but it is a very complicated phenomenon in case of step-growth polymerization. In this study, a more detailed interpretation of the meaning of the flow index $n$ is presented. The results, obtained with two models of rotational viscometers of similar working principle but of different technical characteristics, are compared.

\section{EXPERIMENTAL}

Rheological measurements were performed for different batches of six UF resins indicated by numbers from 1 to 6 . Resins $1 \mathrm{a}$ and $1 \mathrm{~b}$ were synthesized in our laboratory (300-400 g), 2a, 2b, 3a, 3b, 3c, 4, 5 and 6 are commercial resins. A typical three-step procedure was used by the synthesis of resins 1, 2, 3, 5 and 6 , the synthesis conditions ( $\mathrm{pH}$, temperature and time) could be different. For comparison, the resin 4 was synthesized without the first hydroxymethylolation step. All resins had the F/U molar ratio within limits of 1.04-1.06. Standard characteristics (Table 1) were obtained by methods described previously $\left[{ }^{9}\right]$ and lie in the limits required for low-toxic resins for producing adhesively-bonded wood particleboards (PB).

Two different rotational viscometer models with defined shear rate were used for measurements: Brookfield RVDV-II+ programmable viscometer with small sample adapter and Rheotest-2 (Prüfgerätewerk Medingen). Both viscometers are 
Table 1. Standard characteristics of UF resins

\begin{tabular}{|c|c|c|c|c|c|c|c|c|c|c|}
\hline \multirow[t]{2}{*}{ Characteristics } & \multicolumn{10}{|c|}{ Resin } \\
\hline & $1 \mathrm{a}$ & $1 b$ & $2 \mathrm{a}$ & $2 b$ & $3 a$ & $3 b$ & $3 \mathrm{c}$ & 4 & 5 & 6 \\
\hline $\mathrm{pH}$ at $25^{\circ} \mathrm{C}$ & 8.6 & 8.2 & 9.2 & 8.8 & 8.8 & 8.8 & 8.9 & 8.8 & 8.3 & 9.1 \\
\hline $\begin{array}{l}\text { Dry solids, } \% \\
105^{\circ} \mathrm{C}, 3 \text { hours }\end{array}$ & 67.7 & 70.4 & 70.1 & 70.5 & 69.9 & 69.6 & 69.7 & 69.9 & 69.5 & 68.7 \\
\hline Density at $25^{\circ} \mathrm{C}, \mathrm{kg} / \mathrm{m}^{3}$ & 1276 & 1290 & 1288 & 1291 & 1280 & 1280 & 1293 & 1285 & 1289 & 1278 \\
\hline Viscosity at $25^{\circ} \mathrm{C}, \mathrm{mPa} \cdot \mathrm{s}$ & 417 & 487 & 483 & 377 & 437 & 345 & 382 & 292 & 326 & 451 \\
\hline $\begin{array}{l}\text { Gel time at } 100{ }^{\circ} \mathrm{C} \\
\qquad\left(1 \% \mathrm{NH}_{4} \mathrm{Cl}\right), \mathrm{s}\end{array}$ & 61.6 & 63.6 & 65.5 & 47 & 56.2 & 56.5 & 54.4 & 53.4 & 68.3 & 54.2 \\
\hline Water tolerance at $25^{\circ} \mathrm{C}^{*}$ & 3 & 3 & 2 & 2 & 4 & 3 & 3 & 6 & 2 & 2 \\
\hline $\begin{array}{l}\text { Solubility in water at } 25^{\circ} \mathrm{C}, \\
\% \text { of resin }\end{array}$ & 47.5 & 54.2 & 47.8 & 49.2 & 53.2 & 50.0 & 50.0 & 58.5 & 47.6 & 48.0 \\
\hline $\begin{array}{l}\text { Methylol groups, } \\
\% \text { of dry solids }\end{array}$ & 19.6 & 17.9 & 17.3 & 19.7 & 18.5 & 18.1 & 21.4 & 20.9 & 18.2 & 18.5 \\
\hline
\end{tabular}

of coaxial-cylinder-type devices but technical parameters, including the size of cylinders, the shape of rotor and the shear rates used are different (spindles No. 21 and 27 with shear rates of $0-186 \mathrm{~s}^{-1}$ and $0-68 \mathrm{~s}^{-1}$, respectively, for Brookfield; shear rates of $1-437.4 \mathrm{~s}^{-1}$, for Rheotest-2). Viscosity was measured at $25 \pm 0.1^{\circ} \mathrm{C}$. Particular attention was paid to the method of ageing the resin samples $\left[{ }^{9}\right]$. During measurements, requirements of ISO 3219:1993 $\left[{ }^{10}\right]$ were followed.

Viscosity change during resin storage was measured and described by a power law function (1) between shear stress and shear deformation rate, which enables direct evaluation of the consistency index $K$ and power law index $n\left[{ }^{1,8}\right]$. The viscosity values extrapolated to zero and to infinite shear rates, $\eta_{0}\left(\eta_{\max }\right)$, and $\eta_{\infty}\left(\eta_{\min }\right)$, were also obtained on the basis of the power law

$$
\begin{gathered}
\eta=\tau / \dot{\gamma}=K \dot{\gamma}^{n-1}, \\
\log \eta_{0}=\log K+(n-1) \log \dot{\gamma}, \\
\log \eta_{\infty}=\log K+(1-n \log (1 / \dot{\gamma}) .
\end{gathered}
$$

Viscosity value, marked $\eta_{50}$ and named midpoint viscosity, is the interpolated value of viscosity to torque $50 \%\left[{ }^{8}\right]$. All calculations are performed using Microsoft Excel common applications.

\section{RESULTS AND DISCUSSION}

According to technical requirements, immediately after production the resins have rather similar characteristics (Table 1). It is generally known that some 
reactions, occurring during resin synthesis, continue at lower temperatures at which they are stored $\left[{ }^{5}\right]$. The result is a change in the macromolecular structure of the resin, which usually is expressed in an increase of the viscosity and leads finally to the loss of flowability (gelation). It has been found that the stability of various types of resins during storage is different $\left[{ }^{9}\right]$. In the present study, the gelation of the resins took place within about 26-42 days (Fig. 1).

The dependence of the viscosity on time is often used for characterization of storage stability of resins. In $\left[{ }^{6,9,11}\right]$ the time of gelation was calculated using the dependence of the storage time on reciprocal viscosity $\eta^{-1}$ by linear extrapolation it to 0 . We have found that in the case of storage at $25^{\circ} \mathrm{C}$, the linear dependence seems not to be a good approximation. A better result can be achieved when the straight line is plotted only through the points from the end period of the storage, and the points from the initial period of storage, which deviate from this dependence, are not considered. In Fig. 2, calculation of the gelation time with the same method for resins $3 b, 4,5$ and 6 is represented. It is clearly seen that the difference in gelation time among studied resins depends mainly on the duration of the period of storage when the viscosity growth is slow. The same conclusion was drawn in $\left[{ }^{8,9}\right]$.

In $\left[{ }^{8}\right]$, the dependence of the viscosity on the storage time was described by the power law, using the classical rate equation for the description of the polymer network formation. The viscosity $\eta$, the kinetic factor $k$ and the average order of non-linear polycondensation $n^{\prime}$ were the parameters considered in this approach:

$$
\begin{gathered}
\mathrm{d} \eta / \mathrm{d} t=k \eta^{n^{\prime}}, \\
\log (\mathrm{d} \eta / \mathrm{d} t)=\log k+n^{\prime} \log \eta .
\end{gathered}
$$

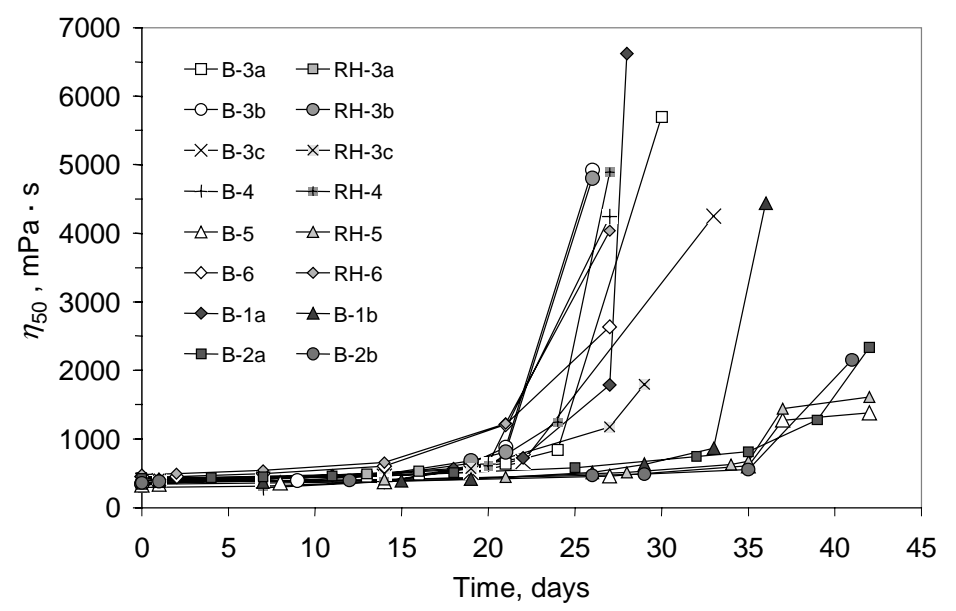

Fig. 1. Dependence of the midpoint viscosity $\eta_{50}$ on the storage time; B denotes the Brookfield and RH the Rheotest-2 viscometer. 


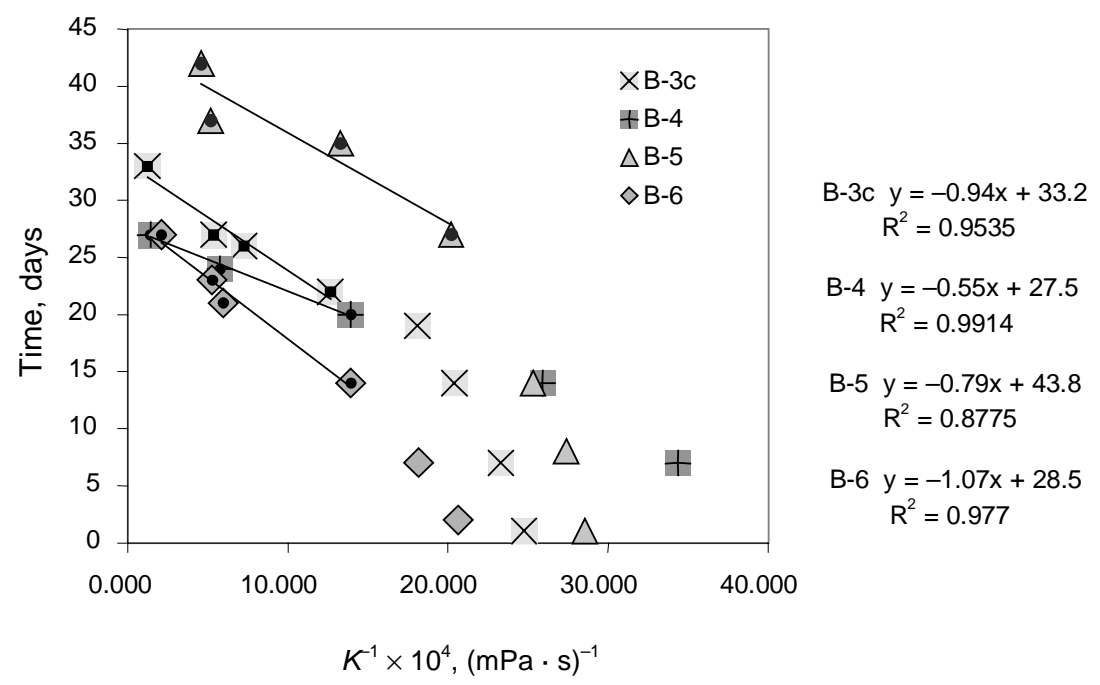

Fig. 2. Dependence of the storage time on $K^{-1}$; measurements were made with the Brookfield viscometer.

A conclusion was drawn that the behaviour of a resin can be described by power law, but not starting from viscosity values typical for fresh resin (300$450 \mathrm{mPa} \cdot \mathrm{s})$. In this initial period of ageing, the viscosity growth in time is slow, which leads to a great deviation from the power law. Paper $\left[{ }^{9}\right]$ confirms the conclusions drawn.

In this study we are concerned with the rheokinetic behaviour of the resins during the initial period of storage, when the viscosity growth is slow. In Table 2, rheokinetic data $n, K\left(\eta_{0}\right)$ and $\eta_{\text {min }}\left(\eta_{\infty}\right)$ are presented.

The flow index $n$ (power law index) is known as "the measure of the degree of non-Newtonian behaviour". For Newtonian liquids $n$ has the value of 1 , and the smaller it is the more non-Newtonian is the liquid $\left.{ }^{1}\right]$. Because of the complicated structure of UF resins it is far from easy to interpret the physicalchemical meaning of $n$, whereas their non-Newtonian behaviour depends both on chemical reactions and physical interactions between molecules of very different size and reactivity. In the initial period of storage, when the midpoint viscosity $\eta_{50}$ is less than $1000 \mathrm{mPa} \cdot \mathrm{s}$, the value of $n$ deviates slightly from 1 . It means that the non-Newtonian character of the resins is weakly expressed immediately after production and during some time at storage. As one can see from Table 2, data obtained with Brookfield and Rheotest-2 viscometers differ from each other, depending on the differences in shear deformation conditions (the size of cylinders, the shape of the rotor and the shear deformation rates used).

Values of the flow index $n$, calculated from the data obtained wiht Brookfield and Rheotest- 2 viscometers differ from each other by about 0.1 unit. It can be explained by different conditions of deformation. The better or worse agreement 
Table 2. Rheokinetic data of UF resins stored at $25^{\circ} \mathrm{C}$ (until $\eta_{50}<1000 \mathrm{mPa} \cdot \mathrm{s}$ and for the last sample before gelation)

\begin{tabular}{|c|c|c|c|c|c|c|c|c|c|}
\hline Resin & Days & $n$ & $K\left(\eta_{0}\right)$ & $\eta_{\min }\left(\eta_{\infty}\right)$ & Resin & Days & $n$ & $K\left(\eta_{0}\right)$ & $\eta_{\min }\left(\eta_{\infty}\right)$ \\
\hline \multicolumn{5}{|c|}{ Brookfield } & \multicolumn{5}{|c|}{ Rheotest-2 } \\
\hline \multirow[t]{4}{*}{$3 a$} & 13 & 0.992 & 469 & 452 & $3 a$ & 7 & 0.905 & 662 & 428 \\
\hline & 21 & 0.984 & 682 & 634 & & 13 & 0.907 & 721 & 469 \\
\hline & 24 & 0.968 & 936 & 808 & & 16 & 0.900 & 793 & 501 \\
\hline & 30 & 0.773 & 9305 & 3270 & & & & & \\
\hline \multirow[t]{4}{*}{$3 b$} & 9 & 0.994 & 407 & 396 & $3 b$ & 7 & 0.933 & 546 & 401 \\
\hline & 14 & 0.989 & 492 & 466 & & 14 & 0.912 & 891 & 463 \\
\hline & 21 & 0.928 & 1112 & 792 & & 21 & 0.883 & 1229 & 715 \\
\hline & 26 & 0.677 & 9820 & 2222 & & 26 & 0.644 & 9230 & 1789 \\
\hline \multirow[t]{4}{*}{$3 c$} & 7 & 0.995 & 429 & 419 & $3 c$ & 7 & 0.927 & 615 & 440 \\
\hline & 14 & 0.986 & 490 & 458 & & 14 & 0.921 & 690 & 478 \\
\hline & 22 & 0.953 & 790 & 637 & & 22 & 0.881 & 1067 & 622 \\
\hline & 33 & 0.722 & 8087 & 2246 & & 29 & 0.749 & 3644 & 1147 \\
\hline \multirow[t]{4}{*}{4} & 7 & 0.998 & 291 & 289 & 4 & 7 & 0.882 & 538 & 313 \\
\hline & 14 & 0.995 & 386 & 377 & & 14 & 0.880 & 638 & 372 \\
\hline & 20 & 0.966 & 718 & 619 & & 20 & 0.856 & 1083 & 557 \\
\hline & 27 & 0.768 & 6988 & 2397 & & 27 & 0.680 & 8561 & 1963 \\
\hline \multirow[t]{5}{*}{5} & 8 & 0.997 & 365 & 360 & 5 & 14 & 0.909 & 616 & 405 \\
\hline & 14 & 0.991 & 395 & 379 & & 21 & 0.898 & 680 & 425 \\
\hline & 27 & 0.981 & 495 & 454 & & 28 & 0.890 & 793 & 479 \\
\hline & 35 & 0.950 & 752 & 603 & & 35 & 0.840 & 1250 & 597 \\
\hline & 42 & 0.862 & 2180 & 1156 & & 42 & 0.743 & 3396 & 1037 \\
\hline \multirow[t]{4}{*}{6} & 2 & 0.982 & 484 & 446 & 6 & 2 & 0.907 & 721 & 471 \\
\hline & 7 & 0.974 & 550 & 488 & & 7 & 0.902 & 798 & 508 \\
\hline & 14 & 0.954 & 718 & 579 & & 14 & 0.861 & 1121 & 591 \\
\hline & 27 & 0.789 & 4727 & 1791 & & 27 & 0.681 & 7598 & 1775 \\
\hline
\end{tabular}

between the viscosity values $\eta_{0}$ and $\eta_{\infty}$, computed from Brookfield and Rheotest-2 viscometers' data, is partly due to methods used to compute them (see Eqs. (3) and (4)). There is a better agreement between calculated values of $\eta_{\infty}$. This value of viscosity, using a simplified explanation, does not involve chain interactions, associative interactions with water and entanglement effects in branched and crosslinked polymer clusters $\left[{ }^{8}\right]$. As an example, the dependence of $\eta_{\infty}$ on time in the initial period of storage for some resins is depicted in Fig. 3. From the relationship between $\eta_{\infty}$ and flow index $n$ (Fig. 4) we can draw conclusions about changes in the structure of resins due to polycondensation during storage, which are related to the changes in the degree of non-Newtonian properties. Graphs from data of parallel measurements with the two viscometers demonstrate that despite different values of $n$, trendlines of linear relationships have similar slope. Difference in the trendline slopes of the resins studied is 
comparatively small but characteristic (Table 3 ). The greater is the absolute value of the slope, the bigger is the change in non-Newtonian properties of the resin occurring with the rise of viscosity during polycondensation reactions.

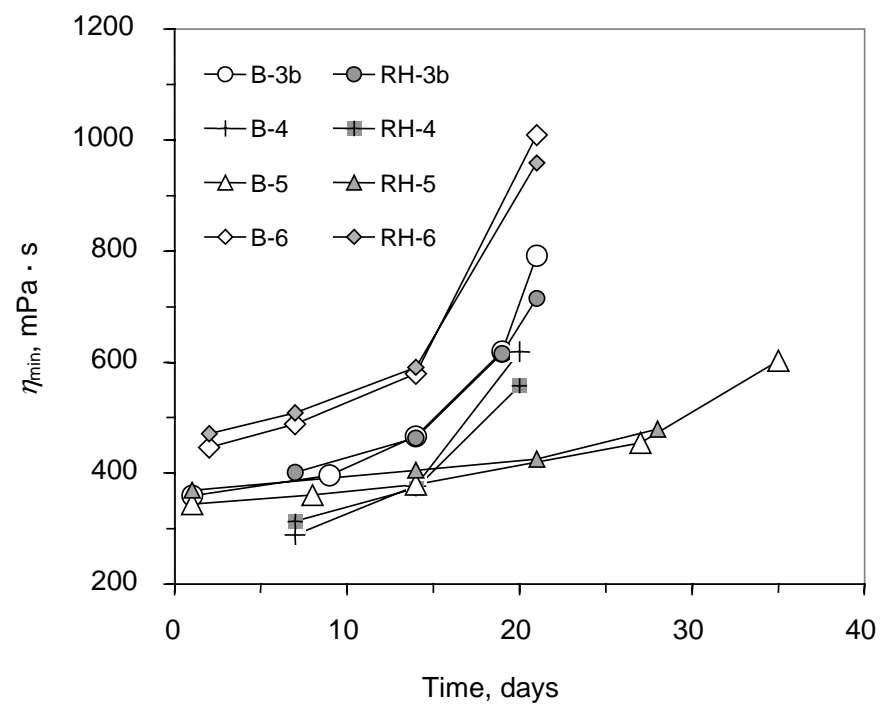

Fig. 3. Dependence of the minimal viscosity $\eta_{\min }$ on the storage time during the initial period of slow viscosity growth for resins 3b, 4, 5 and 6; B denotes the Brookfield and RH the Rheotest-2 viscometer.

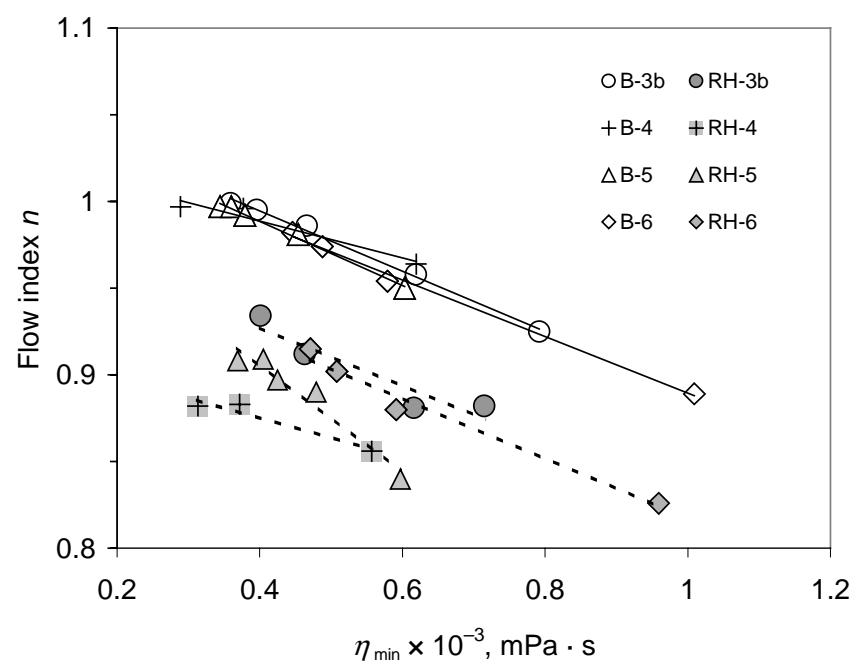

$$
\begin{aligned}
\text { B-3b } y=-0.1733 x+1.0638 \\
R^{2}=0.9948 \\
\text { RH-3b } y=-0.1683 x+0.9946 \\
R^{2}=0.8841 \\
\text { B-4 } y=-0.1069 x+1.0314 \\
R^{2}=0.9463 \\
\text { RH-4 } y=-0.116 x+0.9217 \\
R^{2}=0.9306 \\
\text { B-5 } y=-0.185 x+1.0626 \\
R^{2}=0.9924 \\
\text { RH-5 } y=-0.181 x+0.9769 \\
R^{2}=0.8298 \\
\text { B-6 } y=-0.1629 x+1.0524 \\
R^{2}=0.9955 \\
\text { RH-6 } y=-0.1736 x+0.9905 \\
R^{2}=0.9771
\end{aligned}
$$

Fig. 4. Relationship between the flow index and the minimal viscosity $\eta_{\min }$ for resins $3 b, 4,5$ and 6; $\mathrm{B}$ denotes the Brookfield and RH the Rheotest-2 viscometer. 
Table 3. Calculated rheokinetic parameters

\begin{tabular}{l|c|c|c}
\hline Resin & $\begin{array}{c}\text { Slope of the trendline of the } \\
\text { function } n=f\left(\eta_{\infty}\right), \\
\text { absolute value }\end{array}$ & $\begin{array}{c}\text { Slope of the trendline of the } \\
\text { function } n=f\left(\eta_{0}\right), \\
\text { absolute value }\end{array}$ & $\begin{array}{c}\text { Gel time, } \\
\text { days }\end{array}$ \\
\hline 3a & 0.060 & 0.046 & 30.1 \\
4 & 0.111 & 0.064 & 27.6 \\
6 & 0.168 & 0.119 & 28.5 \\
3b & 0.171 & 0.088 & 25.5 \\
5 & 0.183 & 0.110 & 43.6 \\
3c & 0.204 & 0.106 & 32.5
\end{tabular}

In analogous to Figs. 3 and 4 graphs, where $\eta_{0}$ is used in place of $\eta_{\infty}$, the difference in the behaviour of the resins is not so distinctly expressed. Great differences in $\eta_{0}$ values, obtained with different viscometers, disturb finding regularity in rheological properties of resins. The average slope of the function $n=f\left(\eta_{0}\right)$ was calculated for six resins (Table 3 ). The zero shear viscosity $\eta_{0}$ can be taken as the maximum viscosity of the resin at the determined conversion degree $\left[{ }^{8}\right]$ and it includes therefore the maximum influence of physical interactions. This approach seems to be suitable for explanation of the great variation in viscosity measurement results at small shear deformation rates.

As it is seen in Fig. 4, the relationship $n=f\left(\eta_{\infty}\right)$ relates non-Newtonian behaviour of the resin to the rise in viscosity during the polycondensation reaction. Therefore we preferred to use the slope of the linear trendline of the function $n=f\left(\eta_{\infty}\right)$ as an additional rheokinetic parameter for more profound study. Its correlation with values of some standard characteristics of the resins was examined using Fig. 5.

In Fig. 5, the relationship between the values of some characteristics of the resins (Table 1) and absolute value of the slope of the trendline of the function $n=f\left(\eta_{\infty}\right)$ is presented. As the units and values of the characteristics in Fig. 5 are different, the slopes of the trendlines are not absolutely comparable. The positive or negative tendency in the variation of different standard characteristics can be observed with the growth of the slope of the trendline of the function $n=f\left(\eta_{\infty}\right)$. For instance, properties of the resins were selected, which should characterize the structure of the resins more expressively.

The quantity of water needed for coagulation of a colloidal solution is undoubtedly connected with the structure of the system. It is not easy to find exact mathematical relationships due to the complicated structure of the UF resin. At the same time, it is quite understandable that the less is the solubility of the resin in water and water tolerance, the greater is the polycondensation degree and the degree of non-Newtonian behaviour. Graphs in Fig. 5a show the logical trend of this relationship. In practice, water tolerance is one of the characteristics which is often avoided for low accuracy of measurement, but it is worth to pay more attention to the improvement of accuracy of the measurement method. 

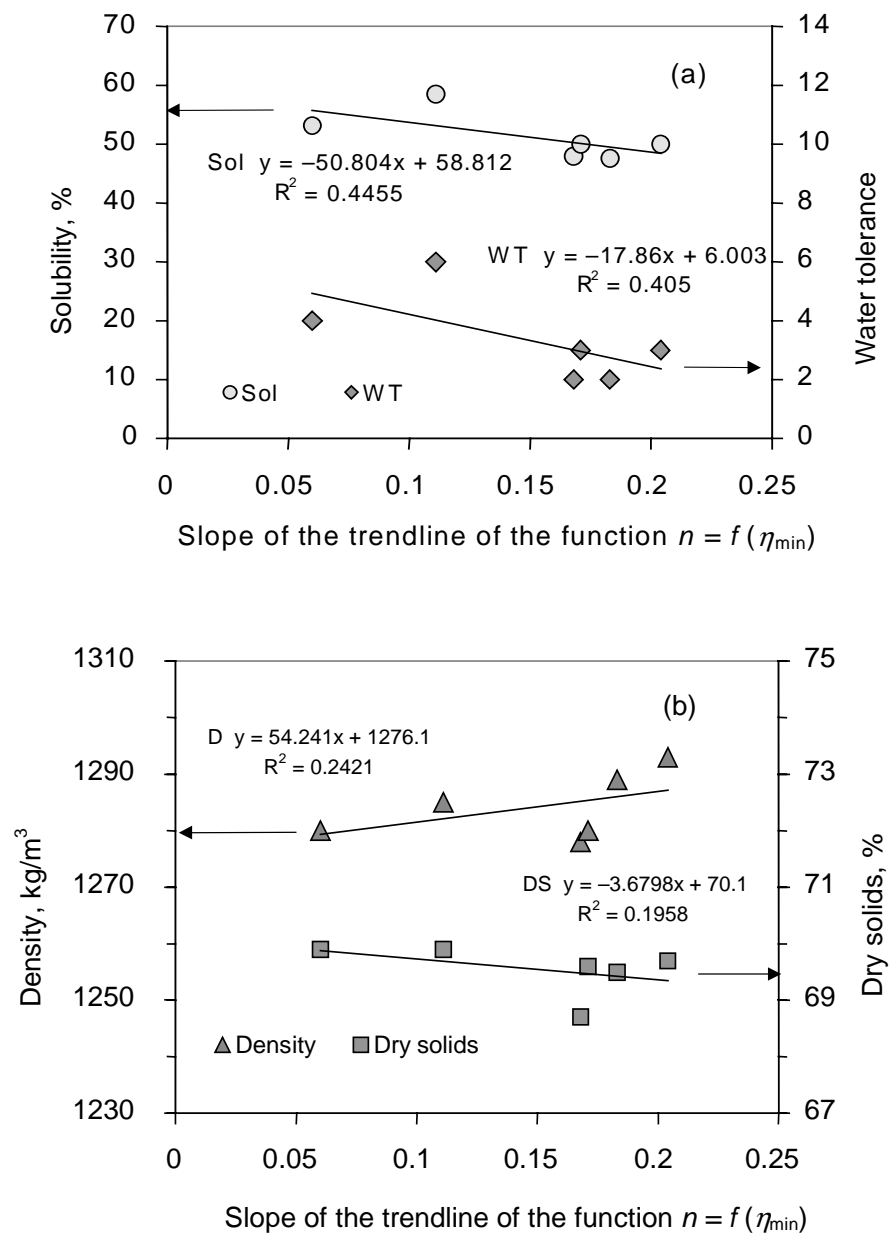

Fig. 5. Relationship between standard characteristics of the resins and the slope of the trendline of the function $n=f\left(\eta_{\min }\right)$, computed from rheokinetic data; Sol - solubility in water, \% of resin; WT - water tolerance, parts of water to 1 part of resin; D - density, $\mathrm{kg} / \mathrm{m}^{3}$; DS - dry solids, $\%$.

For rheological measurements, a particularly important characteristic is the content of dry solids, which has a great influence on the value of viscosity. For this study resins were used with similar content of dry solids, if possible. In Fig. 5b relationship between the slope of the trendline of the function $n=f\left(\eta_{\infty}\right)$ and dry solids and density is presented. Positive trend of density, plotted against the slope of the trendline of the function $n=f\left(\eta_{\infty}\right)$, shows that the more non-Newtonian is the resin, the greater is the value of density (the lower is the concentration of lowmolar-mass components, for example, of unbound urea). Contrary to our presumption, the trend of dry solids is negative. From the plot of density against dry solids (Fig. 6) we can see that values of dry solids of the resins 3, 4 and 5 really lie in the limits of the permissible error of measurements $( \pm 0.25 \%)$, there- 


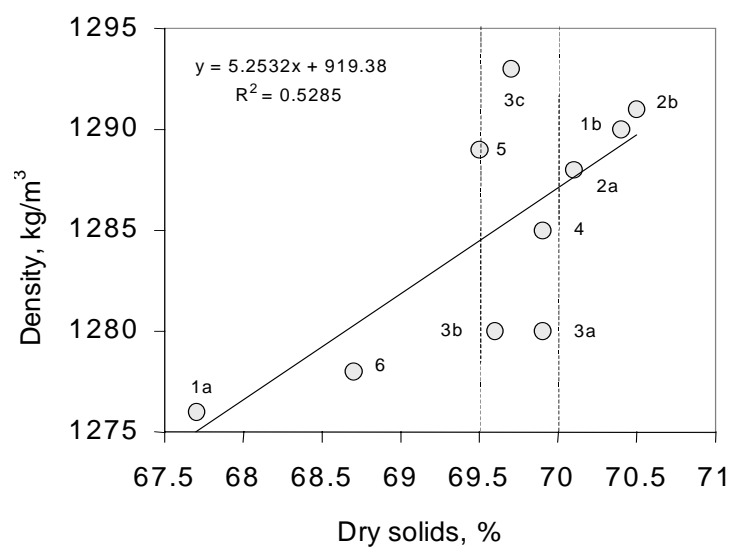

Fig. 6. Plot of the density versus dry solids.

fore variation of density values is not caused by the content of dry solids and may be related to non-Newtonian properties. Content of dry solids of other resins differs appreciably.

In Fig. 7 the relationship between the absolute value of the slope of the trendline of the function $n=f\left(\eta_{\infty}\right)$ and gel time is presented. Neither the gel time evaluated from rheokinetic data nor the gel time measured at $100^{\circ} \mathrm{C}$ with $1 \% \mathrm{NH}_{4} \mathrm{Cl}$, show noticeable dependence on non-Newtonian behaviour. The same we can say about the concentration of methylol groups, measured iodometrically.

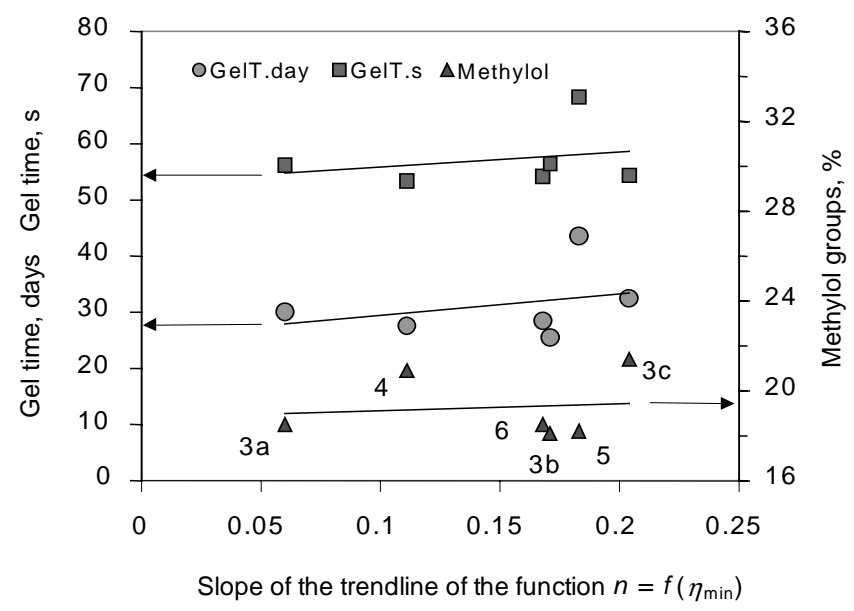

Fig. 7. Relationship between standard characteristics and the slope of the trendline of the function $n=f\left(\eta_{\min }\right)$ computed from rheokinetic data; GelT.d - gel time evaluated from rheokinetic data, days; GelT.s - gel time at $100{ }^{\circ} \mathrm{C}$ and with $1 \% \mathrm{NH}_{4} \mathrm{Cl}$, s; Methylol - methylol groups, $\%$ of dry solids. 
Measurement data shown in Fig. 7 can be expressed as:

GelT.s: $\mathrm{y}=26.72 \mathrm{x}+53.17, \mathrm{R}^{2}=0.066$

GelT.days: $\mathrm{y}=38.28 \mathrm{x}+25.58, \mathrm{R}^{2}=0.101$

Methylol: $\mathrm{y}=3.266 \mathrm{x}+18.78, \mathrm{R}^{2}=0.014$

For comparison, relationships between the gel time, calculated from rheokinetic data and some standard characteristics of the resin are presented in Fig. 8.

Functional relationships are as follows:

GelT.s: $\mathrm{y}=0.300 \mathrm{x}+47.75, \mathrm{R}^{2}=0.126$

Methylol: $\mathrm{y}=-0.060 \mathrm{x}+21.06, \mathrm{R}^{2}=0.117$

Viscosity: $\mathrm{y}=1.942 \mathrm{x}+333, \mathrm{R}^{2}=0.051$

Dry solids: $\mathrm{y}=0.052 \mathrm{x}+67.81, \mathrm{R}^{2}=0.228$
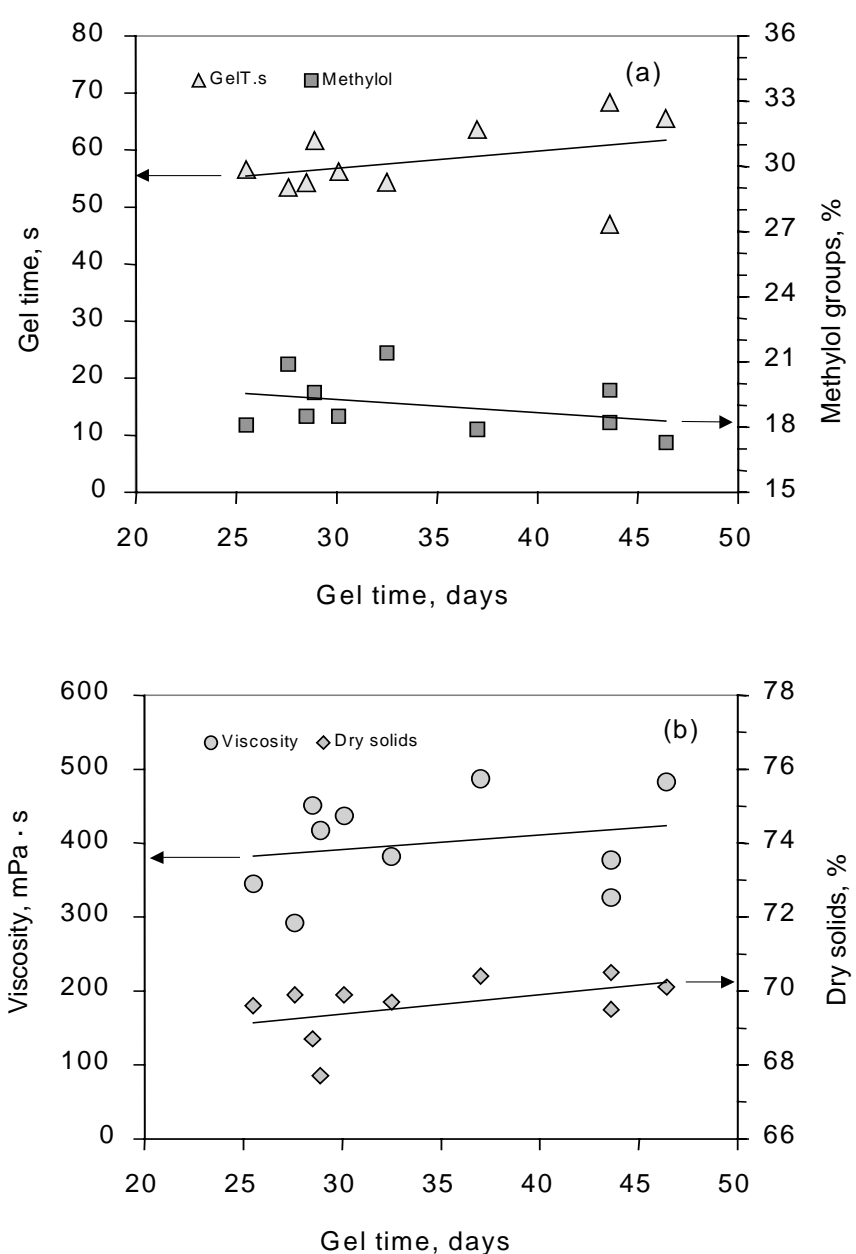

Fig. 8. Correlation of the gelation time, computed from rheokinetic data, and standard characteristics of the resin. 
Trends of graphs in Fig. 8a are logical, but correlation is not good, maybe because of great deviation of some resins (gel time at $100^{\circ} \mathrm{C}$ ), or by too low accuracy of the measurement method (methylol groups). Values of viscosity seem to have no essential meaning on the duration of gelation (stability of the resin). The role of the value of dry solids (or, concentration of water in the resin), needs more profound study.

The fact that in rheokinetic calculations the data from the initial period of storage deviate from regularities, which are valid for the data from the main period of polycondensation, was discussed in a previous study $\left.{ }^{8}\right]$. It was explained by linear polycondensation reactions, proceeding in the initial period mostly in the low-molecular part of the resin. The polycondensation of urea with hydroxymethylurea, formed due to the migration of formaldehyde from the resinous part, is the best example. The reaction mechanism of urea-formaldehyde resins during room temperature storage is analogical to the mechanism of alkaline polycondensation in UF synthesis $\left[{ }^{4}\right]$.

\section{CONCLUSIONS}

Using rotational viscometry for study of different urea-formaldehyde resins, measurement data were systematized using power law functions with the evaluation of the consistency index $K$ and flow index $n$. It was found that immediately after manufacture, when according to the requirements of users the viscosity of resins is in the limits of $300-450 \mathrm{mPa} \cdot \mathrm{s}$, the rheological characteristics give insufficient information, because in the case of most resins studied the nonNewtonian behaviour, e.g. shear thinning, is weakly expressed. During storage of the resins in alkaline conditions, where both, chemical and physical, structures change, their rheological characteristics become more differentiated.

It is suitable to differentiate two periods of the gelation process - the initial period of slow viscosity growth and the following period of fast structuration. The change in the values of the power law index $n$ of resins in the initial period is not great. Values of $n$, calculated from data obtained with two models of rotational viscometers, may be different, but the regularity in their variation is similar. It gives the opportunity to characterize the non-Newtonian behaviour of the resins using measurements during a relatively short time.

Rheological characteristics are mostly useful for the comparison of UF resins, which have relatively similar standard characteristics, particularly the F/U molar ratio and content of dry solids. For rheokinetic calculations, measurement data of controlled accuracy are needed.

\section{REFERENCES}

1. Barnes, H. A. An examination of the use of rotational viscometers for the quality control of non-Newtonian liquid products in factories. Appl. Rheol., 2001, 11, 89-101. 
2. Barnes, H. A., Schimanski, H. and Bell, D. 30 years of progress in viscometers and rheometers. Appl. Rheol., 1999, 9, 69-76.

3. Tomita, B. and Hatono, S. Urea-formaldehyde resins, III. Constitutional characterization by carbon-13 Fourier transform NMR spectroscopy. J. Polym. Sci., 1978, 16, 2509-2525.

4. Kim, M. G., No, B. Y., Lee, S. M. and Nieh, W. L. Examination of selected synthesis and room-temperature storage parameters for wood adhesive-type urea-formaldehyde resins by ${ }^{13}$ C-NMR spectroscopy, V. J. Appl. Polym. Sci., 2003, 89, 1896-1917.

5. Christjanson, P., Siimer, K., Pehk, T. and Lasn, I. Structural changes in urea-formaldehyde resins during storage. Holz Roh-Werkst., 2002, 60, 379-384.

6. Kulichikhin, S. G., Voit, V. B. and Malkin, A. Ya. Rheokinetics of urea-formaldehyde resins gelation. Rheol. Acta, 1996, 35, 95-99.

7. Halász, L., Vorster, O., Pizzi, A. and Alphen, J. A rheological study of the gelling of UF polycondensates. J. Appl. Polym. Sci., 2000, 75, 1296-1302.

8. Christjanson, P., Suurpere, A. and Siimer, K. Rheological behaviour of urea-formaldehyde resins. e-Polymers, 2004, 37, 1-10.

9. Suurpere, A., Christjanson, P. and Siimer, K. Rheokinetic study of urea-formaldehyde resins at ageing. Chemine technologija (Kaunas, Lithuania), 2005, 36, 16-21.

10. ISO 3219:1993. Plastics - Polymers/resins in the liquid state or as emulsions or dispersions Determination of viscosity using rotational viscometer with defined shear rate.

11. Suurpere, A., Siimer, K. and Christjanson, P. Characterisation of urea-formaldehyde resins by their rheological behaviour during storage. In Proc. Baltic Polymer Symposium. Tallinn, 2001, 294-299.

\title{
Rotatsiooniviskosimeetria karbamiidformaldehüüdvaikude uurimiseks
}

\author{
Aime Suurpere, Peep Christjanson ja Kadri Siimer
}

On kirjeldatud rotatsiooniviskosimeetria kasutamist tööstuslike karbamiidformaldehüïdvaikude vanandamise uurimisel. Mõõtmistulemusi on töödeldud astmefunktsiooni abil, arvutades konsistentsi ja voolamise indeksid $K$ ja $n$. On näidatud, et polükondensatsiooniprotsessis on otstarbekas eristada esialgset aeglast viskoossuse tõusu järgnevast kiirest struktureerumisest. Reokineetilise uuringu tulemusi on seostatud karbamiidformaldehüüdvaikude standardanalüüsi näitajatega. 